\title{
$\mathrm{Ke} \mathrm{Yu}^{\star}$ and Elmé Vivier
}

\section{Speaking or being Chinese: the case of South African-born Chinese}

DOI 10.1515/ijsl-2015-0021

\begin{abstract}
Language is often seen as an important symbol and marker of identity. The relationship between the two especially comes to the fore in the experience of immigrants who often must negotiate competing pressures on their identities and language usage. In this article we examine the link between language and identity through an exploration of the lived experiences of four Chinese individuals in South Africa. Drawing on interview data, we examine their language and identity shifts and the factors driving such shifts (or lack thereof). Our analysis reveals multiple degrees and expressions of Chinese identity, of which language is sometimes but not always relevant. We find that social and historical contexts shape the needs and motivations of the individual, who often uses language strategically and flexibly to emphasise or understate particular identities. We conclude that the situational view of the language-identity relation is more appropriate to explain the weak and strong language-identity links that occur at the micro-level.
\end{abstract}

Keywords: language, identity, Chinese, context of reception, social constructivism

\section{Introduction}

Apartheid South Africa established race as the primary determinant of identity politically, economically and socially. This racial identity in many cases reinforced ethnic groupings of those who share common ancestral experiences, homeland, cultural practices, and language among other things. The Chinese in South Africa are no exception. Subject to discrimination and spatial segregation over the course of the twentieth century, the Chinese in the country exemplify an immigrant community's struggle to negotiate competing identities and demands for different language usage. In this article we trace the shifts in identity and language affiliations in the lived experiences of four South African-born Chinese

\footnotetext{
*Corresponding author: Ke Yu, Human Sciences Research Council, Pretoria, South Africa, E-mail: kyu@hsrc.ac.za

Elmé Vivier, Department of Business Management, University of Pretoria, and Human Sciences Research Council, South Africa, E-mail: elmevivier@up.ac.za
} 
(SABCs). ${ }^{1}$ The article draws on qualitative interview data from a study of Chinese communities in Pretoria, South Africa. Although the participants are all 2nd generation immigrants, their experiences extend over a lengthy historical period that includes the transformation of the South African apartheid context, and illuminate why Chinese identity and language ability may or may not have shifted during this time. We explore the relationship between language and identity through these shifts and their driving factors.

The article begins with a brief look at the literature on the relation between language and identity, followed by a historical review of the experiences of the earliest Chinese immigrants in South Africa. Thereafter we present the research methodology and a biographical summary of the four SABCs. We then explore their perceptions around the meaning of identity and language practices through an analysis of four factors that shaped their environment: the context of reception; the organisation of the Chinese community; socio-economic needs; and family dynamics. We find great heterogeneity in their experiences of these four factors, resulting in varying degrees of affiliation with a Chinese identity. In the discussion section we elaborate on the implications of this for understanding the language-identity link, and conclude that language is a flexible strategic resource for continuous identity construction as the individual interacts with dynamic situational forces.

\section{The language-identity nexus and the immigrant experience}

Literature on the language and identity nexus is divided: one perspective denotes a strong link while the other takes a more situational view (although these should be seen to exist along a continuum). Some scholars consider the relationship between language and cultural identity to be interdependent and inseparable (Guardado 2008; Fishman 1991). Supporters of this view generally believe that language is more than a tool for communication and information exchange, but is a conditional marker of identity, closely linked with tradition and collective mythology (May 2000). Every time one speaks a language, one is also organising the sense of who one is and how one relates to the social world (Norton 2000). In fact, the link between language and identity is believed to be so strong that language use alone is taken as sufficient to identify someone's membership in a

1 Some refer to themselves as South African Chinese, others as Chinese South Africans, each reflecting how they relate to South Africa and identify with being Chinese. 
given group (Kamwangamalu 2007). This strong-link argument has also been used to advocate for the preservation of minority languages (May 2000).

On the other hand, the situational view, as we will refer to it in this article, highlights the importance of examining particular historical and social contexts to understand identity and language use. Scholars taking this view claim that language and identity are not fixed and cannot be considered in isolation from social practices and membership (Miller 2000; Phinney et al. 2001b). This perspective reverberates with the notion of social identity, taken up in disciplines from sociology to developmental and social psychology, which refers to "the idea that an individual's self-concept is derived, to some extent and in some sense, from the social relationships and social groups he or she participates in" (Brewer 2001: 117). These groups (or identities) may be based on shared experiences, beliefs, traits, roles, interests and/or language, and are further subject to change over the course of a person's lifetime.

The complexity of the language-identity nexus especially comes to the fore in the context of immigrant and minority groups. On the one hand, language plays a central role in the process of culture and identity preservation among immigrants: mother tongue symbolises origins, early memories, common ancestry, shared values and beliefs. Thus, "retaining a native language is a crucial index of the preservation of cultural roots after immigration" (Sears et al. 2003: 427). On the other hand, linguistic adjustments are essential to the processes of adaptation and "fitting in" (Tannenbaum 2005). For example, Tannenbaum (2005: 229) reports a positive relationship between host language proficiency and the immigrant's economic, academic, professional and personal well-being. In this instance, language becomes a tool that provides the immigrant/minority individual with access to socio-economic resources and additional social groups and roles. The situational view argues that these practically-motivated shifts in language do not necessitate a shift in identity. Phinney (1998), for example, observes that many immigrants living in Europe often maintain a strong ethnic identity independent of language use.

At a macro-level, generational analyses of immigrant communities record a three-stage process that begins with increased pressure on immigrants to speak the language of the host country, followed by a period of bilingualism and concluding with the total replacement of their original language (May 2000: 366). This threestage pattern is similarly evident with regard to identity shifts (Edwards 2004). This parallel shift in both identity and language over three generations seems to support the strong link thesis where changes in one presuppose changes in the other. However, such macro-level analysis does not account for potential differences between individuals, or for other factors that may also be at play. In the rest of this article we examine this potential variation at the micro-level in the lived 
experiences of South African-born Chinese in Pretoria. We focus on the micro-level because it is through individual life stories that perceptions around the meanings of identities and language practices are revealed.

\section{The Chinese in South Africa}

The first Chinese in South Africa arrived in the late 1870s. ${ }^{2}$ They came mainly from Guangzhou province and settled in the former Transvaal (what is today Gauteng Province) as well as in various coastal areas. While many Chinese were attracted to the country by the discovery of gold, anti-Chinese sentiment and racial discrimination prevented them from obtaining mining contracts. As a result, most became shopkeepers and general dealers (Accone 2006). Key policies and legislation (e.g. Law 3 of 1885) determined where they could live, what they could do, and what they could own (South African History Online 2014, hereafter referred to as SAHO). Almost all aspects of life were regulated: citizenship, travel, allowed profession, trade, area of residency, land/property purchasing rights, inter-racial marriage, etc. (Yap and Man 1996). The formation of the South African Union in the early 1900s further disenfranchised all nonEuropeans, and the 1913 Native Land Act formally divided the land between white and non-white people. The election of the National Party to government in 1948 also heightened the enforcement of segregationist policies in the already divided country. The Group Areas Act (1950) in particular began a process of "total segregation between the races", which in many cases involved so-called "forced removals" of some groups into areas designated for their race (SAHO 2014). In addition to general race-based legislation, the Chinese during this time were further subjected to exclusively anti-Chinese policies.

Given this context, it should come as no surprise that many Chinese "continue[d] to look to mainland China as "home", finding a sense of comfort in "an increasingly distanced and mythologised China" (Park 2008: 54). According to Park, this emotional attachment became an enduring point of belonging: "China, both political and cultural, the real and the imagined, provided the Chinese in South Africa with an identity 'refuge' and fulfilled their need to belong" (Park 2008: 76). As early as the 1930s, the segregation of racial groups motivated the Chinese to organise themselves through social clubs, sports groups and Chinese

2 Scholarship on the Chinese in South Africa distinguish between this early group of settlers who are today considered South African-born Chinese (SABCs), Taiwanese who began arriving in large numbers from the 1970s onwards, and newer immigrants from the People's Republic of China (PRC) who began arriving since the late 1990s. 
schools (Yap and Man 1996), especially in the larger Chinese communities such as those in Johannesburg and Port Elizabeth. Alongside these efforts, they also tried to improve their situation through continual concession-seeking petitions and negotiations, often based on their distinct Chineseness (Park 2006: 219). However, "the more they succeeded in becoming acceptable to white society [...] the less they needed their imagined China” (Park 2008: 76). Many SABCs interviewed by Park (2008: 112), for instance, “credited apartheid with keeping the community together" and thus "viewed their acceptance into white schools and white society ... as the beginning of the end of Chinese culture".

Over the course of the twentieth century and into post-1994 democratic South Africa, the Chinese identity was challenged, strengthened and diminished in various ways. In the next section we explore the extent to which various factors impacted on the language and identity shifts of the SABCs.

\section{Research methods}

\subsection{Research site and methods}

This article draws on a case study of the Chinese communities living in Pretoria, South Africa (Houston et al. 2013). The study explored the social roles of Chinese associations in the lives of three distinct Chinese communities, namely the SABCs, the Taiwanese, and the recent immigrants from the People's Republic of China (PRC). Although the study did not directly examine the languageidentity nexus, it was a strong undercurrent for many respondents in terms of their overall lived experiences. The affiliation with local Chinese associations also suggested an ongoing influence of a Chinese-oriented community on individual identities and practices.

Pretoria is the administrative capital of South Africa. Although just some 60 kilometres north of Johannesburg, it has historically been much less cosmopolitan, especially during apartheid. The Chinese community in Pretoria (including SABCs, Taiwanese and more recent PRC immigrants) is relatively small, forming less than $2 \%$ of the population (approximately 54,000) compared to almost 5\% (approximately 216,500) in Johannesburg (IHS Global Insight 2013). One of our interviewees estimated that there are roughly 200 SABCs in Pretoria today.

A total of 26 in-depth interviews were conducted. A snowball sampling method was used where interviewees were identified through personal contacts, organisational websites and desktop research, and further referrals were then requested. Interviews with the SABCs were conducted in English. They were 
assured confidentiality and therefore only pseudonyms are used in this article. The recorded interviews were transcribed verbatim by a professional service provider and quality assured by the researchers. The data was analysed in conjunction with available literature on immigrant communities and on the Chinese in South Africa.

For the purpose of this article we selected four SABCs whose stories show the pronounced heterogeneity of individual language and identity profiles. Although they are all 2nd generation immigrants, they vary in age (and thus period of immigration), as well as in Chinese language ability. While the sample is small, the range of their experiences provides a glimpse of the complex, fluid and multi-dimensional nature of identity and the perceived roles of language therein. The biographical sketches in Section 4.2 and Table 1 provide a general indication of each person's language abilities and affiliation with Chinese and South African identities.

Table 1: $S A B C$ language abilities and identity affiliations.

\begin{tabular}{|c|c|c|c|c|}
\hline \multirow[t]{2}{*}{ Name } & \multicolumn{3}{|c|}{ Chinese language abilities } & \multirow[t]{2}{*}{ Identity } \\
\hline & Listen & Speak & Read/Write & \\
\hline Bill & $\begin{array}{l}\text { Fluent } \\
\text { Cantonese }\end{array}$ & $\begin{array}{l}\text { Fluent Cantonese; with } \\
\text { parents ( } 100 \% \text { of the time) } \\
\text { and older SABCs ( } 90 \%) \\
\text { No Mandarin }\end{array}$ & None & $\begin{array}{l}\text { Claims to be South African, but } \\
\text { socialises largely with other } \\
\text { SABCs. Chinese ethics very } \\
\text { important to him. }\end{array}$ \\
\hline James & $\begin{array}{l}\text { Fluent } \\
\text { Cantonese } \\
\text { Little } \\
\text { Mandarin }\end{array}$ & $\begin{array}{l}\text { Fluent Cantonese; } \\
\text { with older SABCs (65\%) } \\
\text { No Mandarin }\end{array}$ & None & $\begin{array}{l}\text { Feels both South African and } \\
\text { Chinese. Currently active in SABC } \\
\text { community associations and } \\
\text { affairs. }\end{array}$ \\
\hline Andrew & $\begin{array}{l}\text { Fluent } \\
\text { Cantonese } \\
\text { Some } \\
\text { Mandarin }\end{array}$ & $\begin{array}{l}\text { Fluent Cantonese; with } \\
\text { grandparents (100\%) } \\
\text { Fluent Mandarin (for } \\
\text { business in China) }\end{array}$ & None & $\begin{array}{l}\text { Claims to be fully South African, } \\
\text { but participates in local SABC } \\
\text { associations and events and } \\
\text { children go to Chinese School. } \\
\text { Social circle comprises local } \\
\text { South Africans. }\end{array}$ \\
\hline Sarah & $\begin{array}{l}\text { Little } \\
\text { Cantonese }\end{array}$ & None & None & $\begin{array}{l}\text { Feels half Chinese, half South } \\
\text { African. Plans to instil Chinese } \\
\text { culture in her children. Friends } \\
\text { mostly local South Africans. } \\
\text { Engaged to a South African. }\end{array}$ \\
\hline
\end{tabular}




\subsection{Interviewee biographies}

\subsubsection{Bill}

Bill was born in 1944 in a black township near Pretoria. His grandfather moved to Johannesburg as a businessman around 1904, and although Bill's father was born in South Africa, he went to school in China. Bill attended the Pretoria Chinese School (PCS) for most of his primary schooling. As an adult he worked for a long time in so-called black areas, eventually opening up his own accounting firm in a predominantly white urban neighbourhood. Bill has on occasion gone to China to visit extended family, and also keeps up with what goes on in China through English television. He participates in some Chinese associations in Pretoria and his social circle comprises mainly other SABCs. He tries to instil what he believes is a Chinese work ethic (e.g. being productive) in his family and workplace, although he considers himself to be a South African.

Bill still speaks fluent Cantonese, usually with his family and other older SABCs, but he speaks mostly English with his daughter. He is also proficient in Sesotho, one of the indigenous languages in South Africa, which he believes helps his interactions with Black South Africans.

\subsubsection{James}

James was born in 1959 in Marabastad, a township near Pretoria. After attending a local Indian school and the PCS, James became one of the first Chinese in Pretoria to be granted admission to a private white high school established by a Catholic church. ${ }^{3}$ After school he managed his father's hardware store. While he was not very active in the Chinese community due to family and professional commitments at the time, he still spent weekends and social time with Chinese friends at the Chinese School. Currently he is much more involved with the local Chinese organisations. Although James insists that he will always be Chinese, he also describes South Africa as home: "because this is where I was born; my roots are here".

According to James, his experience in the English school taught him that language can be a barrier or enabler for social and business interactions. His poor English was often the subject of teasing and made it feel degrading to be

3 From the 1930s onwards, it became possible for non-whites to attend private white schools established by Catholic churches on the basis of their conversion to Christianity (Yap and Man 1996: 303). 
Chinese. He therefore worked hard to improve his English while also retaining Cantonese. Today he speaks mostly English, although he is still fluent in Cantonese and uses it when interacting with older SABCs.

\subsubsection{Andrew}

Andrew was born in 1971. His grandparents immigrated in the 1930s, and his mother was born in South Africa and his father in China. He attended the PCS before going to an English high school. Today his two children are also enrolled in the PCS. While he attends local Chinese functions and assists with fundraising for various Chinese associations, his social circle comprises his family as well as local South African friends. Andrew considers himself to be fully South African culturally and socially. He associates the Chinese identity and culture with that of mainland China today, which he finds foreign to his own, as he explains in the following quote: "I may just look like a Chinese outside, but I'm nothing like Chinese inside."

Despite this strong South African identity, Andrew can speak Cantonese and Mandarin relatively well, although he describes it as "kitchen Chinese" that he feels ashamed to speak among other Chinese. His Afrikaans (the language of the Afrikaners) is better than his Chinese, and he speaks mostly English at home and with friends. He learned Cantonese as a child as it was the only way to communicate with his grandparents, and learned Mandarin through the Chinese School and some Taiwanese friends. Today he uses this language skill mostly with his parents and as an informal translator during business trips to China.

\subsubsection{Sarah}

Sarah was born in 1990 in Hong Kong and brought to South Africa as a baby by her adopted parents. Growing up in Pretoria she attended private English schools. Most of her friends today, including her fiancé, are South African. While she sometimes attends functions organised by the Chinese community, this is mostly at her parents' request. Although she does not socialise in the local SABC community, she is still proud to be a "Chinese South African". Her sense of being Chinese remains distinct from China though, which for her is simply the place of her birth and home of her ancestors. Instead, she describes how her parents have taught her aspects of Chinese culture through specific practices (e.g. the honouring ceremony, giving tea with two hands), which she plans to teach to her children as well. 
Sarah does not speak any Chinese language, but has some minimal understanding of Cantonese. Her parents speak English and Cantonese with one another and used to speak Cantonese to her when she was younger. They also sent her to a Saturday Chinese language school for a while, but none of this succeeded in motivating her to learn the language. The small number of SABCs in her generation, who mainly speak English, has also created little incentive for her to speak Chinese.

Table 1 provides a summary of the language abilities and generalised identity claims of the four SABCs.

\section{Factors influencing language and identity}

Factors that influence immigrant experiences provide a lens for examining identity and language shifts at the micro-level, as well as perceived meanings of identity and language usage. In the case of the SABCs in Pretoria, we found four key factors influencing their experiences: the context of reception; the organisation of the Chinese community; the need for social mobility and advancement; and family needs and efforts. These factors are by no means unique to the South African Chinese case and are, among a number of other factors, ${ }^{4}$ relevant to immigrant experiences across the globe. As part of a larger narrative, the details of these individual life stories demonstrate how such factors are not uniformly "felt". They also do not impact the immigrant experience independently from one another but together influence perceptions and actions in multiple and complex ways.

\subsection{Factor 1: the context of reception}

One of the primary factors, at least for the older generation of SABC interviewees, has been the hostile context of reception created by apartheid. "Context of reception" refers to the general attitude of the host society towards an immigrant community, and is considered "an important factor for understanding the group's integration into, acceptance of, and success in a host society" (Doucet 2003: 78). In instances of real or perceived hostility, "immigrants may downplay or reject their own ethnic identity", or they may "assert their pride in their cultural group and emphasise solidarity as a way of dealing with negative attitudes" (Phinney et al. 2001b: 494). Daha (2011: 563) finds for instance that

4 Other factors include demographic variables such as Socioeconomic Status (SES), length of residency in the host country, age at the time of immigration, and gender. These are beyond the scope of this article. 
negative stereotyping of Iranians by Americans strengthened the Iranians' loyalty to their ethnic identity, "even when many had not travelled to Iran and could not speak the language well".

In the case of the SABCs, our interviewees' experiences reveal how the antagonistic context of South Africa reinforced their sense of Chineseness. Both Bill and James recall the impact of racial discrimination and segregation, such as having to ask permission to work and/or reside in white neighbourhoods. As with the Iranian example, this hostile environment actually kept the Chinese community closer together. Bill described the experience as follows:

(1) ... because of the apartheid system, we were a very close knit company ... I always say it's a consolation to live among our own people. You don't have to know everyone, but because of apartheid, it's always better to be among your group.

South Africa's transition to democracy since 1994 has however changed this environment, as well as the SABCs' attachment to their community, as the two younger SABCs (Andrew and Sarah) illustrate. Although Andrew has some memories of being one of the only Chinese in an English school, and of discrimination when his family bought a house in a white area in the 1980s, he admits never really being bothered by a sense of being different. This suggests that the influence of even a generally negative context of reception depends on how it is received by the individual.

Sarah feels the most distanced from this hostile past, which is understandable given her age. This was evident in her reflections on a 2008 Black Economic Empowerment (BEE) court case. The case was raised by the SABC community (through the Chinese Association of South Africa) against several national government departments in an attempt to challenge the exclusion of the Chinese from the new government's affirmative action policies. After nearly eight years of lobbying and legal efforts, the court confirmed that the Chinese are indeed also "previously disadvantaged" due to apartheid (Huynh et al. 2010). But Sarah distinguishes this from her experiences growing up:

(2) I'm very happy that they got it for their generation. But for my generation, I don't think we need it because we didn't grow up in the struggle that they had. We grew up in multiracial schools. We became friends with blacks, whites, Indians and everybody.

These four cases illustrate how the nature of the context of reception can reinforce an attachment to a particular identity, be it a heritage/ethnic identity 
or a more localised one. While we have not discussed the impact of the context of reception on language use and ability, this seems to occur through its influence on the next three factors.

\subsection{Factor 2: organisation of the Chinese community in Pretoria}

Studies show that community organisation often provides institutional and social support to immigrants or minorities (Lieber 2010; Zhou and Lin 2006). Such organisation is usually more feasible in large, concentrated communities where individuals can join cultural organisations, share cultural practices and values, and form a cohesive "speech community" (Lai 2012). In cities where the immigrant community is small and dispersed, however, cultural participation and exposure is limited, and thus learning and maintenance of home language may decline and sense of ethnic identity may weaken. As discussed earlier, in the large Chinese communities such as in Johannesburg, their crucial mass is said to have sustained such community associations, clubs, schools, and festivals (Park 2008: 112). In Pretoria however, the community was relatively small, yet some key organisations were also established as early as the 1930s.

Of particular importance to the Pretoria Chinese was the establishment of the PCS. Schools that teach the heritage language have been recognised as being "of the greatest importance in sustaining the language" (Edwards 1985: 147). Beyond language retention, these schools often provide opportunities for social networks and transmission of culture through the observation of events and celebrations (Francis et al. 2009). This has also been the case with the PCS, which aimed at providing a quality education for Chinese children, as well as teaching Chinese language (originally Cantonese and switching to Mandarin in the 1970s due to teacher availability), and preserving Chinese culture and identity (Yap and Man 1996: 283). The school quickly became the centre of the SABCs' social engagements, providing facilities for other local community associations, sports activities, religious meetings, and cultural celebrations. Drawing on his experience of discrimination in an English school, James speculates that many Chinese parents sent their children to the PCS during apartheid in order to avoid racist attitudes. In this sense, the school protected their ethnic identity.

Many SABCs today however seem not to have a strong attachment to the Chinese organisations or Chinese community. This is apparent in the low Chinese enrolment rate at the school $(10 \%$ of the total student population, including Taiwanese and PRC children). It is also evident in the lives of Sarah and Andrew. Sarah never attended the PCS and it could be argued that this is one of 
the reasons for her lack of Chinese language skills. Andrew on the other hand exhibits a paradoxical attitude towards Chinese language and culture. Although he placed his children in the Chinese School to expose them to Chinese culture, they do not observe any Chinese practices or speak any Chinese languages at home. He also plans to eventually move them to an English school because he believes it will be more "like the real world" and will provide more opportunities for them.

\subsection{Factor 3: the need for socio-economic mobility and advancement}

The SABCs' efforts to find their place in the South African community were also influenced by the desire and/or need for socio-economic advancement, as the experience of James shows. Being one of the first to attend a private white school, James was among the early examples of the SABCs' shift in interest from Chinese to English education because of the need for "upward economic mobility" (Park 2008: 82). Park's observations seem to reverberate with those of John Edwards in his seminal work, Language, society and identity (1985). Edwards argues that security and freedom (or other pragmatic needs) often preoccupy minority groups much more than the concerns over culture or language, especially in the face of increasing urbanisation, in-migration, and socio-economic pressures. In this sense, maintaining one's heritage language may bar social access and mobility by the minority groups (Edwards 1985: 96). The relatively low Socioeconomic Status (SES) of the early Chinese immigrants, alongside the oppressive apartheid state, could have meant that practical concerns were more pertinent in their approach to language and identity because they did not have the "psychological and economic capital" (Edwards 1985: 94) for "luxury" concerns over identity.

Prizing the value of success over the value of language has been observed in several studies of overseas Chinese communities as well. For example, Zhang (2004: 45-46) finds that Chinese immigrants often encourage their children to shift to English as soon as possible in order that they may achieve success academically and in their future careers. Similarly, Kim and Chao (2009) conclude that the transfer of Chinese values (often with an emphasis on success) among second generation Chinese in Los Angeles was significant in maintaining a sense of ethnic identity despite language loss.

\subsection{Factor 4: family needs and/or parental efforts}

Parental efforts are another factor in retaining a sense of Chinese identity or Chinese language ability. Family dynamics and parents' efforts to transfer 
cultural awareness and values to their children are especially significant where there is little contact with the culture of origin (Suarez-Orozco 2004). Parents who believe that their ethnicity is important are likely to engage in cultural behaviours, thus promoting this identity in their children (Phinney et al. 2001a: 138). Similarly for language, Shin (2010: 216) asserts that, "successful language learning and maintenance strategies usually ... start with language transmission at the level of the family".

Sarah's sense of Chineseness as well as her lack of Chinese language ability may be attributed in large part to her parents' efforts to transmit values and cultural practices. However, despite her parents' efforts, she has not developed a desire to learn Chinese. While she still feels Chinese in some ways (and observes traditional practices at home), her friends and school experiences have influenced her attitude towards the Chinese language. Sarah's case therefore reflects the significance of the interplay of social environment and individual choices on language usage.

The need for family communication also sometimes drives the effort to retain the heritage language. James for instance maintained his Cantonese despite attending English-speaking schools, which could be attributed to his parents' and grandparents' limited English. While in the example of Andrew, the passing of generations led to a decreased need to use Chinese as a communicative language. Similar experiences have been noted by Park in her study of SABCs who, with the passing of older generations, "lost both the impetus and opportunity to practise the language” (Park 2008: 109).

This review of SABC experiences illuminates some of the key factors that may impact on immigrants' retention and/or loss of their language and ethnic identity. It shows the complexity of being an immigrant (or minority) group in a changing environment, as well as the tensions accompanying individual identity claims and language practices. In Section 6 we discuss the fluidity of SABC identity affiliations and what it implies for the link between language and identity.

\section{Discussion}

\subsection{The heterogeneity and fluidity of SABC identities}

The four case studies confirm a general weakening over time of both Chinese language proficiency and Chinese identity. However, they also show a fluid coexistence of Chinese and South African identity affiliations. What becomes especially apparent is the multiple degrees and expressions of Chineseness, and 
the complex variety of "markers" defining this identity, of which language is but one. Thus we see all four SABCs describe themselves as South African, ${ }^{5}$ aligning their culture with white South African culture and distinguishing it from that of contemporary Chinese. And yet, a sense of being Chinese also remains, although their perceptions of this identity and how they practice it vary widely. For instance, for Bill and James, their Chineseness is embedded in their experiences within a particular socio-political history and the social community with whom they share this history. It is lived out through continued social interactions of the SABC community and local SABC organisations, their continued use of Cantonese as the medium of conversation, and the public observation of particular Chinese holidays and events. Sarah's and Andrew's attachments to their Chineseness (or SABC identity) comprise different markers. For Sarah, being Chinese is predominantly cultural yet private. It is made possible by her parents' efforts to preserve and observe specific Chinese traditions and ceremonies at home. Language has little if any role in this identity. Andrew on the other hand insists that he is South African, yet he sends his children to the Pretoria Chinese School, attends local Chinese functions, and assists with fundraising for various Chinese associations. He therefore demonstrates continued affiliation with the local SABC community, although without a strong sense of belonging. His practical use of the Chinese language also, paradoxically, reflects his Chinese heritage yet reinforces for him the gap between himself and those whom he sees as "real Chinese".

\subsection{The role of language in the fluidity of identities}

The variety of ways that Chineseness (or identity in general) is perceived and expressed among these four interviewees confirms numerous identity theories that highlight the complex fluidity of continuous identity formation. These theories generally agree that identity is, at least in part, socially constructed. It is derived from one's lived experiences within particular historical, political and social contexts, relationships and roles. It is "negotiated, on-going, changing constantly across time and space” (Wenger 1998: 163). Our study further confirms to an extent the social constructivist paradigm that emphasises the reflective and productive role of the individual in the construction of his or her own identity (Ochs 1993). In this sense, one can be strategic in choosing to display only a certain part of one's identity in a certain situation, or to prioritise

5 An additional layer of complexity arises in the fact that South Africa, with eleven official languages, comprises a variety of cultural groups and languages. 
identities as needed. This has been captured by Cohen (2000: 582) as follows: "One can be Muslim in the Mosque, Asian in the street, Asian British at political hustings and British when travelling abroad, all in a single day”.

These strategic actions echo Jaspal and Coyle's (2009) proposal that identity coping strategies are complex and dynamic. This, we argue, is especially relevant with regard to the language and identity link. When identity is under threat, individuals may "seek to deprecate the importance of aspects which pose a threat to the positive evaluation of one's identity" (Breakwell 1986, quoted in Jaspal 2009: 19), including the "denigration of the language" (Jaspal and Coyle 2009: 163). Thus one may downplay or embrace both heritage language and identity, or one may downplay only heritage language while maintaining one's heritage identity. Language thus becomes a "dynamic symbolic object that can be applied strategically in identity making" (Lauring 2008: 344).

Due to the flexibility of language, one could also expect more strategic use of language (compared to other identity markers) in the presentation of particular identities. An individual may adopt a new language, combine different languages into a single linguistic system (Woolard 1998), or select a particular vocabulary or accent to reflect a social/group identity or role (Jaspal 2009). Furthermore, acquiring a new language may be desirable as it is usually positively received in the host environment as a demonstration of the willingness to adjust to the host culture, and also invokes less sense of betrayal and objection within the heritage community given the practical functions it serves.

Flexible coping strategies in the production of identity also illuminate the influence and interplay of various factors and how these are perceived and addressed at the individual level. Different strategies may be used in different circumstances, as is evident in the narratives of the four SABCs. James learned English in order to fit in at school, yet still speaks Cantonese fluently when he is with other SABCs. Learning English was therefore a strategy to protect rather than simply diminish his Chinese identity. Andrew on the other hand, as mentioned above, feels less Chinese whenever he speaks the Chinese language due to his "poor" ability. Each social actor therefore experiences various factors through their individual needs, motivations, and a multitude of identities, which further influences language and identity choices. For this reason, a language and cultural identity that is initially linked could at the same time be impacted differently and even in opposite directions. This challenges the expectation that language and identity shifts occur together as held by the strong link thesis. At the micro-level, individual experiences of historical and social contexts reveal how the link between language and identity, far from being deterministic and static, is rather multiple, complex, and contextually specific. 


\section{Conclusion}

This micro-level study of four South African-born Chinese, although too small to make conclusive generalisations, has brought to light the dynamic and highly variable manner in which the meanings of identities and languages are perceived and expressed. Thus, even though there seems to be a general shift occurring away from a strong Chinese identity and Chinese language usage, each of the four individuals retained some degree of attachment to being Chinese and Chinese language abilities. However, they also define this Chineseness differently, appealing to shared socio-political experiences as Chinese during apartheid, specific cultural practices and traditions, and sometimes language. Their experiences illuminate how the interplay of environmental, social, and individual factors continually influence the place of different languages (alongside other identity markers) within one's self-concept. Language can therefore be a strategic yet flexible symbolic resource for managing tensions and shifts between varying identities.

Furthermore, the interplay of the socio-historical context and individual needs and motivations emerges as a driving force behind identity and language choices and the link between the two. From the lens of only four contextual factors, we find for example a situation where a negative context of reception that emphasises difference is reinforced by a positive family environment that protects that difference, while simultaneously a difficult school experience pushes an individual to strategically undermine that difference (as in the example of James). In this interplay of factors, the relationship between language and identity can strengthen or weaken as it is influenced by emotional and pragmatic needs and experiences. For instance, this relationship may remain strong as an individual retains his or her heritage language and culture in the face of an adverse environment (more likely with the support of an organised community and similar family efforts). It may also however remain closely linked while potentially decreasing in relevance overall as an individual adapts to the host society, either learning a new language or changing cultural practices.

Conversely, the link between heritage language and culture may weaken. First, a language shift may occur while other cultural markers and practices are retained. From our case studies we see this occurring through the presence of a shared, organised community, or through a strong family influence. Each of these seems capable of retaining a heritage culture despite a language shift. Sarah's case further suggests that at the family level, and in the absence of a strong heritage culture and language community, cultural practices are more easily passed down than language. Second, heritage language may be maintained 
while identity changes. In the case of Andrew we see how heritage language becomes a functional tool with little deeper cultural value, which is a strong possibility for Chinese given the increased presence of China in the global economy that has increased the language's socio-economic capital.

In conclusion, we propose that the argument for a strong link cannot account for the experiences of the individual, which is precisely where the relationship between language and identity is shaped and plays out. Instead, the situational view of the language-identity link (arguing for a weak relation) is better able to capture the heterogeneity evident at the micro-level as this perspective is able to explain cases of weak and strong language-identity links, as well as the varying degrees in between. The situational view allows that, while there may be a broader shift across a community, identities linger and transform in a continuous process of identity formation and expression. It is precisely this kind of pluralism that characterises human experiences and practices.

\section{References}

Accone, Darryl. 2006. "Ghost people”: Localising the Chinese self in an African context. Asian Studies Review 30. 257-272.

Brewer, Marilynn B. 2001. The many faces of social identity: Implications for political psychology. Political Psychology 22(1). 115-125.

Cohen, Robin. 2000. The incredible vagueness of being British/English. International Affairs 76. $575-582$.

Daha, Maryam. 2011. Contextual factors contributing to ethnic identity development of second-generation Iranian American adolescents. Journal of Adolescent Research 26. 543-569.

Doucet, Fabienne. 2003. Identities and their complexities: A review essay of trends in ethnic identification among second-generation Haitian immigrants in New York City by Flore Zephir. Race and Society 6. 75-82.

Edwards, John. 1985. Language, society and identity. Oxford: Basil Blackwell.

Edwards, John. 2004. Bilingualism: Context, constraints, and identities. Journal of Language and Social Psychology 23. 135-141.

Fishman, Joshua A. 1991. Reversing Language Shift: Theory and Practice of Assistance to Threatened Languages. Clevedon: Multilingual Matters.

Francis, Becky, Louise Archer \& Ada Mau. 2009. Language as capital, or language as identity? Chinese complementary school pupils' perspectives on the purposes and benefits of complementary schools. British Educational Research Journal 35(4). 519-538.

Guardado, Martin. 2008. Language, identity, and cultural awareness in Spanish-speaking families. Canadian Ethnic Studies 40(3). 171-181.

Houston, Greg, Marie Wentzel, Ke Yu \& Elme Vivier. 2013. "Bodies that divide and bind: Tracing the social roles of associations in Chinese communities in Pretoria, South Africa". HSRC Project Report. Pretoria, South Africa: HSRC. 
Huynh, Tu T., Yoon Jung Park \& Anna Ying Chen. 2010. Faces of China: New Chinese migrants in South Africa, 1980s to present. African and Asian Studies 9. 286-306.

IHS Global Insight. 2013. Rex regional explorer database version 2.5n. http://www.ihsglobalinsight. co.za (accessed 25 August 2013).

Jaspal, Rusi \& Adrian Coyle. 2009. Language and perceptions of identity threat. Psychology and Society 2(2). 150-167.

Jaspal, Rusi. 2009. Language and social identity: A psychosocial approach. Psychtalk 64. 17-20.

Kamwangamalu, Nkonko W. 2007. One language, multi-layered identities: English in a society in transition, South Africa. World Englishes 26(3). 263-275.

Kim, Su Yeong \& Ruth K. Chao. 2009. Heritage language fluency, ethnic identity, and school effort of immigrant Chinese and Mexican adolescents. Cultural Diversity and Ethnic Minority Psychology 15. 27-37.

Lai, Daniel W.L. 2012. Ethnic identity of older Chinese in Canada. Journal of Cross Cultural Gerontology 27. 103-117.

Lauring, Jakob. 2008. Rethinking social identity theory in international encounters: Language use as a negotiated object for identity making. International Journal of Cross Cultural Management 8(3). 343-361.

Lieber, Marylene. 2010. Chinese migrants in Switzerland: From mutual assistance to promoting economic interests. Journal of Chinese Overseas 6. 102-118.

May, Stephen. 2000. Uncommon languages: The challenges and possibilities of minority language rights. Journal of Multilingual and Multicultural Development 21(5). 366-385.

Miller, Jennifer M. 2000. Language use, identity, and social interaction: Migrant students in Australia. Research on Language and Social Interaction 33(1). 69-100.

Norton, Bonny. 2000. Identity and language learning: Gender, ethnicity and educational change. London: Longman/Pearson.

Ochs, Elinor. 1993. Constructing social identity: A language socialisation perspective. Research on Language and Social Interaction 26(3). 287-306.

Park, Yoon Jung. 2006. Sojourners to settlers: Early constructions of Chinese identity in South Africa, 1879-1949. African Studies 65(2). 201-231.

Park, Yoon Jung. 2008. A matter of honour: Being Chinese in South Africa. Johannesburg: Jacana Media.

Phinney, Jean. 1998. Ethnic identity and acculturation. Paper presented at the Conference on Acculturation, University of San Francisco, US.

Phinney, Jean, Irma Romero, Monica Nava \& Dan Huang. 2001a. The role of language, parents, and peers in ethnic identity among adolescents in immigrant families. Journal of Youth and Adolescence 30(2). 135-153.

Phinney, Jean, Gabriel Horenczyk, Karmela Liebkind \& Paul Vedder. 2001b. Ethnic identity, immigration, and well-being: An interactional perspective. Journal of Social Issues 57(3). 493-510.

South African History Online (SAHO). 2014. South African history online: Towards a people's history. www.sahistory.org.za (accessed 12 March 2014).

Sears, David O., Mingying Fu, P. J. Henry \& Kerra Bui. 2003. The origins and persistence of ethnic identity among the "new immigrant” groups. Social Psychology Quarterly 66(4). 419-437.

Shin, Sarah J. 2010. "What about me? I'm not like Chinese but I'm not like American": Heritage language learning and identity of mixed heritage adults. Journal of Language, Identity and Education 9(3). 203-219. 
Suarez-Orozco, Carola. 2004. Formulating identity in a globalized world. In Marcelo M. SuarezOrozco \& Desiree Qin-Hilliard (eds.), Globalization: Culture and education in the new millennium, 173-202. California: University of California Press and Ross Institute.

Tannenbaum, Michael. 2005. Viewing family relations through a linguistic lens: Symbolic aspects of language maintenance in immigrant families. Journal of Family Communication 5(3). 229-252.

Wenger, Etienne. 1998. Communities of practice. Cambridge: Cambridge University Press.

Woolard, Kathryn A. 1998. Simultaneity and bivalency as strategies in bilingualism. Journal of Linguistic Anthropology 8(1). 3-29.

Yap, Melanie \& Dainne Leong Man. 1996. Colour, confusion and concessions: The history of the Chinese in South Africa. Hong Kong: Hong Kong University Press.

Zhang, Donghui. 2004. Home language maintenance among second-generation Chinese American children. Working Papers in Educational Linguistics 19(2). 33-54.

Zhou, Min \& Mingang Lin. 2006. Community transformation and the formation of ethnic capital: Immigrant Chinese communities in the United States. Journal of Chinese Overseas 2(2). 193-219. 